\title{
A produção de texto para ingressar no ensino superior: os desafios da docência perante uma escrita protocolar
}

\author{
Composing text for admission into higher learning: the challenges of teaching \\ writing beyond protocol
}

\author{
Sílvia Galesso Cardoso; Adriana Marcondes Machado; Teresa Cristina Rego \\ Universidade de São Paulo
}

\begin{abstract}
RESUMO:
O percurso escolar, da educação básica à superior, está submetido à escrita protocolar que se apoia no senso comum e se afasta de uma prática autoral. Quais ações poderiam provocar rachaduras no uso preponderante dessa escrita protocolar? Este artigo se baseia na investigação de um projeto de doutorado sobre o ensino e a aprendizagem de produção de texto, com estudantes pertencentes a famílias economicamente privilegiadas que se preparavam para concorrer a uma vaga na universidade, em encontros-aula nos quais se pretendeu promover uma escrita singular e em contato com a experiência do escritor. Com o objetivo de analisar os procedimentos desenvolvidos no esforço de romper formas de pensar e escrever submetidas a uma lógica generalizante e normativa, utilizamos registros que foram organizados sobre os percursos com diferentes alunos, apresentamos o contexto em que os encontros-aula se deram, expomos algumas formas de agir em relação a desafios que se formalizaram nessa prática e tecemos algumas reflexões que esse trabalho possibilita em relação à escrita no ambiente acadêmico.
\end{abstract}

Palavras-chave: produção de texto; formação de estudantes; formação de professores

\begin{abstract}
:
The scholastic pathway, from basic to higher education, is subject to a prescriptive form of writing based on common sense, moving away from an autoral practice. Which actions may provoke breaches in the dominant use of this normative writing? This article is based on a doctoral project that investigates the teaching and learning of textual composition, with students belonging to economically privileged families and who were preparing to apply for a place in the university, in writing sessions dedicated to the promotion of a writing that is singular and in contact with the experience of the writer. The present article has the intent of analysing the procedures developed during this effort to disrupt forms of thinking and writing that are susceptible to a generalizing and prescriptive logic by the use of records produced throughout the sessions with different students, by presenting the context in which the writing exercise occurred, by exposing different ways of reacting to the challenges that were formalized in this practice and, finally, by also raising a few considerations regarding writing in the academic environment that were brought to light by these encounters.
\end{abstract}

Key-words: writing composition; student training; teacher training 


\section{A escrita protocolar na formação de estudantes}

A partir de uma experiência de doutorado ${ }^{1}$ referente à pesquisa sobre a escrita e a formação de estudantes, a atividade docente ganhou relevo. Escrever faz parte de qualquer docência, e os docentes que trabalham diretamente com o ensino da produção de texto lidam com resultados empobrecedores de uma escolaridade submetida à lógica empresarial que atravessa a contemporaneidade. A escrita protocolar aprendida no ensino fundamental é perpetuada em um ensino superior em que há um modo gestor de pensar empreendido nas "[...] formas de controle contínuo, avaliação contínua, e a ação da formação permanente sobre a escola, o abandono correspondente de qualquer pesquisa na Universidade, a introdução da 'empresa' em todos os níveis de escolaridade" (DELEUZE, 2013: 229).

Este artigo foca as formas de viver agenciadas nessa lógica, em que muitos estudantes saem de uma escola e passam a frequentar uma universidade na qual a experiência é limitada, pois as ações são direcionadas a responder padrões de comportamento: "[...] infância, educação, sexualidade, uso de drogas, a relação com outros seres vivos e com o planeta, e também o amor, a amizade, a simpatia, até mesmo a morte, deixam de integrar o campo da experiência possível dos indivíduos para se tornarem bens de consumo, investimentos em capital humano." (AVELINO, 2016: 277).

Em meio a esse cenário, propõe-se ativar uma docência que desenvolva uma escrita-experiência na qual o escritor consiga romper padrões de pensamento. Iremos discorrer sobre o trabalho docente em processos de ensino e aprendizagem da escrita de textos com estudantes do ensino médio e analisar possíveis deslocamentos em formas de pensar e escrever submetidas a uma lógica generalizante e protocolar. Apresentaremos o contexto em que os encontros-aula se deram com os jovens pré-universitários e utilizaremos, como material de análise, os registros sobre as várias versões dos textos reescritos pelos estudantes. Ao final, iremos elencar possíveis desdobramentos desse trabalho no ambiente acadêmico ${ }^{2}$.

\section{Procedimentos e elementos em jogo nos encontros-aula}

O contexto disparador das análises aqui apresentadas foi um trabalho realizado 
com alunos pré-universitários desde 2002, em que se desenvolveu a expressão escrita, em aulas particulares e individuais, no intuito de prepará-los para a prova de redação, obrigatória nos exames de admissão em universidades brasileiras. Foram encontros-aula semanais, que duraram em torno de uma hora e meia, normalmente ao longo de um ano, por vezes um semestre apenas, outras vezes alguns anos. Esses encontros podiam ocorrer na casa do aluno ou no escritório de trabalho da professora. O público frequentava escolas ou cursinhos preparatórios particulares da Zona Sul e Oeste de São Paulo e fazia parte das classes média e alta.

Durante esses anos de experiência, pudemos acompanhar a relação entre as exigências dos exames de admissão e os efeitos na forma de escrever dos estudantes. É praticamente unânime a denúncia de que os modos de produção de textos na escola não preparam o estudante para as práticas legitimadas e valorizadas na cultura impressa, porque "as condições de texto não são consideradas e a leitura não é vista como parte do processo de escrita, o que apaga a existência de processos intertextuais e torna a atuação sobre o texto algo restrito a atividades de revisão formal de sua superfície" (PIETRI, 2010: 136). Desse modo, o ensino da escrita restringe-se, predominantemente, a ser uma tarefa a ser cumprida, sem contemplar sua dimensão de linguagem e de interação. A redação do vestibular, além de ser resultado desse ensino uniformizador, motiva-o e torna mais relevante comprovar o domínio de uma forma do que fazer do texto um espaço que possibilite a mobilização de sentido e a construção de ideias.

A análise feita por Pécora (1980), a partir de redações dos candidatos do extinto CESCEM (Centro de Seleção de Candidatos às Escolas Médicas e Biológicas), constatava o fracasso de esses textos funcionarem como uma experiência significativa, em que autor e leitor constituíam um espaço de intersubjetividade. Eles falseavam um "processo ativo de elaboração de um discurso capaz de preservar a individualidade de seu sujeito e de renová-la, desdobrá-la, na leitura de seus possíveis interlocutores" (PÉCORA, 1980: 17) com estratégias de preenchimento. Os estudantes reproduziam modelos consagrados, assimilavam padrões de linguagem e referenciais para interpretar o mundo e, assim, sua escrita limitava-se a ser caricatura deles mesmos. Isso porque tanto a prova de vestibular desconectava o desempenho escrito do uso efetivo da linguagem, quanto a atenção da escola ao ensino da escrita ficava restrita ao componente técnico das condições de escrita, dando prosseguimento à identificação histórica entre escrita e padrão de linguagem e embasando sua prática na falsificação das condições de escrita e no confinamento dela a usos permitidos e aconselháveis. O 
aluno, sem poder recorrer a sua pessoalidade e aos seus interesses, seria obrigado a renunciar a uma escrita significativa e a reduziria a uma reprodução, preocupando-se mais com os procedimentos formais de ocupação do espaço da folha de redação do que com encarar a avaliação como uma atividade de empenho pessoal, uma oportunidade de dizer algo, de refletir, de se divertir e de criar. A concepção de escrita para esses jovens é de "um aborrecido exercício de cristalização de formas, uma redução de seu papel ao papel a ser preenchido." (PÉCORA, 1980: 87).

Rocco (1981) desenvolveu uma pormenorizada pesquisa sobre as redações de candidatos do vestibular da Fuvest de 1978. A grande parte dos textos era ou linear, infantil e baseada apenas em realidades concretas e imediatas, ou pré-fabricada com discursos padronizados e impessoais; ou ainda incompreensível e sem sentido algum. Em apenas 40 dos mais de 1300 textos analisados (2,7\% do total) foi constatada a presença de originalidade, elementos-surpresa ou criatividade. As citações e referências usadas eram quase sempre as mesmas e pareciam ter a intenção de o candidato mostrar erudição e preencher espaço no texto com palavras bonitas, mas alheias a si e abstendose de propor a sua compreensão sobre o tema da redação.

Outra pesquisa que analisou redações dos candidatos ao vestibular é de Brito (2004). A pesquisadora investigou dissertações da Unicamp de 1999, a fim de evidenciar como a subjetividade do candidato se constituía ao longo do texto. Para isso, examinou o posicionamento dele em relação ao tema, o diálogo que estabeleceu com os textos constituintes da proposta e seu estilo (referente aos aspectos linguísticos). Brito concluiu que havia uma oscilação do estudante entre produzir um espaço intersubjetivo no texto, no qual era possível mobilizar e construir sentidos, e reproduzir formas e lugares-comuns, em que só se comprovava o domínio de um modelo. Ela supôs que essa tendência de o sujeito desaparecer na redação do vestibular era efeito de o ensino da escrita em contexto escolar ser preponderantemente homogeneizante, bem como da dissertação ser um gênero caracterizado pela objetividade e pela impessoalidade.

Costa Val (2006) também se dedicou a investigar produções textuais do vestibular de 1983 da UFMG. Ela observou que os textos tinham um desempenho mais satisfatório quanto aos aspectos formais, mas o nível de informatividade e criatividade era insatisfatório: $45 \%$ dos textos analisados eram praticamente iguais, recorrendo aos mesmos argumentos e ao mesmo esquema formal. Essa alta previsibilidade demonstrava que os jovens não se arriscavam em suas produções escritas de vestibular. 
Eram textos pobres, simplistas, entediados, que tinham como efeito uma leitura que não entusiasmava.

A suspeita de Costa Val era de que o estudante teria substituído a originalidade e a decisão do que queria deixar explícito e implícito no texto pelo exercício de preenchimento de esquemas, a mesma suposição de Pécora (1980). Esse comportamento se daria tanto devido às contingências da situação de produção: escrever de improviso, sobre um tema imposto, para um interlocutor temido e desconhecido, quanto em razão da orientação recebida pelos alunos em ambientes educacionais de que a redação de vestibular deve ser impessoal e objetiva. Essa indicação seria a estratégia de professores para evitar que uma abordagem subjetiva do tema fosse compreendida pela banca examinadora como inabilidade do aluno de tratar uma questão com racionalidade e isenção. Apelariam, então, a receitas, esquemas, fôrmas que garantem o bom desempenho do aluno, pelo menos em relação à aprovação na prova. $\mathrm{O}$ aluno, por seu lado, preencheria o modelo de redação recorrendo a lugares-comuns. Essa espécie de adestramento levaria o aluno a uma concepção equivocada do ato de escrever que "se reduz ao exercício enfadonho de preencher" (COSTA VAL, 2006: 127). O estudante, assim, não cria familiaridade com a produção escrita, o que o inviabiliza de descobrir seus próprios métodos de criação textual.

Uma das pesquisas mais recentes sobre redação no vestibular é a de Castaldo (2009), em que foram analisados elementos composicionais (norma linguística, índices de pessoalidade e macroarticulação) da redação dissertativa de candidatos da Fuvest 2007. Nela evidenciou-se que o estudante, preocupado em ter uma boa nota, deixava de levar ao texto seu mundo e suas ideias, para ocupá-lo do que supunha ser o mundo e as ideias de seu interlocutor. Assim, o dever-dizer se impunha e seu saber-dizer se enfraquecia, tornando a redação de vestibular um espaço de confronto e não de negociação, no qual a língua é cindida.

Todos os alunos acompanhados pela pesquisa estavam fazendo aula de redação porque queriam passar no vestibular, embora, para alguns, escrever fosse algo que não estava restrito a essa necessidade, era ação na vida. As diferenças de visão, por certo, tinham efeitos no trabalho e se articulavam com a posição defendida na proposta desses encontros-aula: a escrita é gesto de criação, mesmo em trabalhos com as normas e exigências dos exames vestibulares e tendo a função de ampliar as possibilidades de o aluno passar pelo crivo das instituições universitárias. 
Há uma fronteira a habitar entre o pedido do aluno de as aulas garantirem a entrada no vestibular e escrever como ação no mundo. Interpelar a escrita-protocolar e oferecer algo a mais, a escrita-ação-no-mundo, coincide com um modo de escrever exercitado por Foucault, que toma o: "[...] trabalho escritural como experiência voltada à intensificação de um tipo de pensamento de natureza essencialmente crítica e, igualmente, à produção de uma superfície fática para modos inéditos de existir" (RAMOS DO Ó; AQUINO, 2014: 199).

A escrita, em um pensamento que critica a naturalização do mundo, é compreendida como processo de subjetivação em que se criam resistências a formas de sujeição. A atitude crítica busca por romper com a hegemonia dos modos dominantes de pensar e sentir (DOMÈNECH et al., 2001) que, nesse trabalho, incita uma outra escrita: "[...] pensar de outro modo exige escrever de outro modo, que nossa vontade de um outro pensamento é inseparável de nossa vontade de uma outra escrita, de uma outra língua" (LARROSA, 2004: 15).

Os encontros-aula realizados tinham como propósito preparar os jovens para a prova de vestibular, demandando, para isso, interceder pela escrita pensante do estudante, pela experiência inventiva de escrever, pela produção de textos que produzissem modos de existências inéditos, heterogêneos, sensíveis. Nem sempre esse convite inicial era bem recebido, pois os estudantes compreendiam que, para escrever melhor, bastava seguir certas instruções. Mas, durante o processo, a proposta ia ficando mais clara. A cada encontro, um tema era apresentado ao estudante, a partir de alguns trechos ou pequenos textos de variados autores e fontes. Os assuntos iam dos mais concretos aos mais filosóficos: acontecimentos recentes, como rolezinhos ${ }^{3}$, manifestações de junho de $2013^{4}$, reformas trabalhista e previdenciária ${ }^{5}$; e também questões existenciais presentes em vestibulares anteriores ou criadas nos encontros, como "a fama é essencial ao homem?", "qual a importância da música na vida das pessoas?", "o medo é proteção ou acomodação?", "ainda há espaço para o altruísmo e o pensamento a longo prazo na contemporaneidade?".

Às vezes, um texto escrito exigia 3 ou 4 versões; outras vezes, duas. Durante essas experiências de ensino, a reescrita a partir de comentários e ideias trocadas entre a professora e o aluno tornou-se forma de trabalhar, pois as palavras escritas do aluno ganhavam impacto na discussão sobre os temas desenvolvidos. Essa estratégia 
propiciou o engajamento do aluno com sua escrita, que, tendo um leitor, tornava-se leitor de si mesmo.

O interesse da pesquisa de doutorado em questão tinha o sentido estratégico de que a produção textual dos estudantes fosse tomada como ação no campo da educação. Por isso, a preocupação em desenvolver estratégias discursivas capazes de possibilitar uma aprendizagem que, uma vez formalizada, gerasse deslocamentos em certas formas de pensar generalizantes e protocolares.

Dessa maneira, o estudo assumiu uma perspectiva experiencial e, portanto, processual, em que interessaram os movimentos de negociação entre as ideias e posições antes da produção textual e aquelas que ocorreram a partir da leitura dos excertos e das discussões nos encontros-aula. Tomamos como princípio que toda ideia e posição é sustentada por um regime de verdade sempre em constante construção (VEIGA-NETO, 2007). O desafio da pesquisa foi encontrar, na trama dos acontecimentos habituais, ou seja, já estabelecidos como verdades, instantes que perturbassem a ordem e instalassem a incerteza. Esses instantes permitiam que testemunhássemos lampejos de existências frágeis e intercedêssemos por virtualidades desprezadas (LAPOUJADE, 2017). Para que fosse possível fortalecer a potência do inesperado presente nas incertezas produzidas quando a ordem é perturbada, o trabalho demandou processo, tempo e construção de aliança.

\section{A escrita na vida desses jovens}

O trabalho desenvolvido com os jovens funcionava como uma rede de convocações. Ia-se traçando uma espécie de jogo para perceber e entrar no mundo que cada jovem trazia consigo, penetrar nele para acrescentar ou tirar algo dali, deslocar uma palavra, uma percepção que fosse. A intenção não era virar o mundo do avesso, mas perceber os tais lampejos frágeis que poderiam servir para acrescentar leituras que tensionassem o tipo de mundo e vida que essa juventude vivia, o tipo de relação que estabelecia com as coisas, os fatos, as pessoas e os conceitos que formulava. Havia um modo de ser peculiar que se expressava ali, tecido em um modo hegemônico de ser jovem de classe média e alta em São Paulo, na década de 2010.

Esses jovens não precisavam se preocupar em arrumar trabalho para pagar os estudos, não se dedicavam a serviços domésticos porque contavam com empregados em suas casas, tinham como principal obrigação os estudos, frequentavam muitas atividades extras, viajavam bastante, andavam principalmente de carro com motorista, fosse 
particular ou táxi/uber, e eram cobrados pela escola, pelos pais e por si mesmos a passar no vestibular, tomado como "ritual de passagem" dessa juventude para a vida adulta. A escola tinha grande destaque na experiência desses rapazes e moças e era majoritariamente vivenciada com prazer e admiração. Muitos foram os alunos que contaram sobre experiências escolares que os empolgavam, como grupos de conversa em torno do feminismo, grupos de estudos de literatura marginal, campeonatos de futebol e estudos de campo. Os meios tecnológicos eram usados intensamente por eles, tanto para o social quanto para os estudos, e traziam, claro, ótimas soluções, mas também problemas impensáveis nas relações que estabeleciam consigo e com o mundo. Pelo que se vê nos dados sobre os jovens brasileiros (SPOSITO et al., 2018; SPOSITO; SOUZA, 2014), os em análise na tese de doutorado tinham uma condição mais rara de juventude, de certa forma protegida ou mesmo alienada das outras formas de ser jovem mais recorrentes no Brasil.

Este estudo, baseado em experiências privadas com estudantes oriundos de escolas particulares, permite elencarmos questionamentos sobre a maneira de a educação formal lidar com a produção textual. O Índice de Desenvolvimento da Educação Básica (Ideb) identificou, na última edição de $2017^{6}$, que $97 \%$ dos estudantes de Ensino Médio são da rede pública de educação e apenas 12,2\% dos estudantes frequentam a rede privada. Os municípios que apresentaram desempenho no Ideb da rede pública similar ao observado na rede privada do respectivo estado foram somente $6,5 \%$; todo o restante registrou desempenho dos estudantes do ensino público 2,3 pontos inferior ao daqueles do ensino particular: neste, o índice é igual a 5,8, enquanto naquele é 3,5. Além dessa discrepância e das desigualdades que ela perpetua, chama a atenção ambas as redes educacionais não atingirem 6 pontos, média correspondente ao sistema educacional de países desenvolvidos, o que demonstra que a escolaridade fica em risco, seja pelo ataque empresarial ao ensino privado, seja pelo desmonte da educação pública, que, como mostram as tendências atuais, justificaria sua privatização e permitiria que grandes corporações a dominassem e lucrassem com ela em convênios espúrios com grupos políticos.

Esses meninos e meninas viviam suas juventudes como um momento de vida difícil, exigente, de grandes variações de intensidade interna e externa - auge dos hormônios, das descobertas sexuais, da performance corporal e, junto com isso, a vida social e o mundo se expandindo com mais heterogeneidade. Os padrões e expectativas 
que preponderavam resultavam em uma forma de pressão em que a solidão ficava mais presente. O jovem se percebia como um sujeito com pensamentos independentes, mas com uma vida pouco autônoma; queria ter a liberdade de um adulto, mas não suas responsabilidades; queria se diferenciar de seus pais, mas precisava do aval deles para tomar decisões; opinava sobre tudo, mas não tinha poder total de decisão sobre si mesmo. Um lugar difícil de ser sustentado estava presente na maioria dos textos escritos por esses jovens, em que emitiam uma opinião, mas tinham dificuldade para criar ou apresentar os argumentos que a sustentassem, e o uso dos ambientes virtuais como plataformas de debates parecia fomentar essa opinião apressada.

A exigência, dedicação e tempo que escrever demandava concorriam com o agito, explícito ou implícito, na vida deles, em uma fase de baladas, viagens, namoros, amizades e dúvidas. Não que a escrita fosse entendida como desinteressante em si, mas ela disputava com muitas coisas interessantes, e menos exigentes do que ela: pedia tempo, entrega, mergulho, quase a desconexão total com a realidade compartilhada, uma concentração de horas e horas para entrar em sintonia com a toada vagarosa das frases, com o funcionamento lento e cansativo daquela linguagem em que cada palavra era uma decisão, uma aposta entre outras.

A presença dos pais, na maioria das vezes, podia ser sentida mais pelos investimentos e cobranças do que pela participação no processo de escrita - eles não costumavam ser leitores de seus filhos. As expectativas dessas famílias coincidiam com a necessidade de que cursassem uma faculdade, por isso mesmo as próprias aulas particulares faziam parte, também, daquilo que os jovens consumiam para ampliar sua formação.

O futuro e o mundo se abriam com infinitas possibilidades, mas o mundo deles era apertado, contido, como sua escrita em um texto dissertativo de trinta linhas. Havia os que insistiam em se colocar no texto e então precisavam encontrar um modo de caber no formato, sem perder o singular e as derivas possíveis; e havia os que desistiam, se conformavam e reduziam a escrita ao cumprimento de uma obrigação e ao uso de estratégias de preenchimento.

Osakabe (1977: 58), em sua pesquisa, detecta o problema do raciocínio feito, frequente nas redações de vestibular, em que se fixam modos de abordar um tema e imobilizam-se, assim, novas maneiras de pensar:

[...] mesmo que não se pretenda que os alunos neguem as premissas ditas irrefutáveis, a adoção de certas estratégias, no sentido de que consigam extrapolar o plano de 
premissas óbvias, parece ser condição inicial para a ativação não só de outras premissas, mas para o questionamento do senso-comum, em benefício de uma reflexão. Mesmo que ela não chegue a ser original, que seja ao menos crítica e incorpore experiência pessoal. Sob esse aspecto, é importante observar ainda que o exercício de redação é mais que um adestramento: é o favorecimento de uma atitude no sujeito, atitude essa que não se reduz à sintaxe gramaticalmente correta, mas que envolve necessariamente o debate, a crítica, a informação, a leitura.

Quando o senso comum aparecia nos textos de alguns dos estudantes, estimulavam-se derivas em que eles pudessem acessar seu repertório e sua experiência de vida. As conversas a partir da concretude dos fatos apresentadas nos excertos instigavam os jovens a se colocarem, a problematizarem, a perceberem o que estava em jogo na situação analisada. Um dia, trabalhando sobre o tema do medo, a afirmação vaga de um aluno de que, frente ao temor, "é preciso arriscar para se obterem melhoras", suscitou a pergunta: como a vida reage a tanto medo? E o estudante nomeou o aprisionamento e identificou que a melhora a que se referia seria no sentido de poder usufruir uma vida com mais liberdade. A argumentação de uma aluna, ao escrever sobre participação política, deteve-se na política partidária e governamental. Viu-se uma oportunidade de a interpelar: há formas de fazer política que não a governamental ou partidária? A estudante associou política às lutas feministas, das quais participava, e acrescentou isso ao texto. Para outra estudante que desenvolvia um texto sobre indenização por abandono afetivo, perguntou-se como seria não ter os pais como referência na formação dela. Ela imaginava que seria desestruturante, que a tornaria mais vulnerável às pressões sociais, com menos autoestima, o que a fez explicitar no texto a importância das referências familiares na formação de uma criança. $O$ conformismo, na afirmação de outro jovem de que a chuva era a causa dos deslizamentos, provocou investigar informações sobre o último deslizamento noticiado: ele ocorrera em um morro da periferia de uma cidade litorânea paulista, o que fez o estudante relacionar o deslizamento com a vulnerabilidade dessa população e compor outros elementos na existência dos deslizamentos que não apenas a chuva.

Mas como tudo que remete à pessoalidade tende a ser sentido como um risco, trazer o repertório e a experiência para o texto pedia suporte para o estudante confiar nessa aposta. O jovem era convidado a estar no texto, a lidar com contradições, a fazer escolhas, a propor conciliações, a tomar posicionamentos arriscados, a produzir encadeamentos para a experiência fragmentada preponderante no mundo atual, a 
construir um texto cuja beleza não estaria reduzida às palavras e expressões formais, mas à força de seu processo.

Citaremos algumas situações em que houve deslocamento a partir do que ocorria nos encontros-aula e nos comentários nas várias versões dos textos. Um aluno apresentou a imigração como um negócio lucrativo e, ao ler sobre a situação dos imigrantes, incluiu em sua proposta a necessidade de o governo receber essa população não apenas para ser benéfico ao país, mas também para acolhê-los das situações de vulnerabilidade de que estão fugindo e dar-lhes novas oportunidades. Uma jovem abordou a verticalização e intensa ocupação urbana na metrópole como um movimento natural e, ao ser questionada sobre os embates, as disputas, especulações e luta pela garantia de direitos, acrescentou a seu texto a necessidade de conciliar interesses imobiliários e direitos dos cidadãos. Uma aluna com dificuldade em estabelecer relação entre consumismo, lixo e corrupção, a partir das questões produzidas no encontro-aula, estabeleceu uma relação entre a ganância, o consumo exacerbado e o excesso de lixo. Um estudante, que defendia a reforma trabalhista de forma genérica, conquistou uma ressalva: a reforma seria benéfica ao país, contanto que os direitos dos trabalhadores fossem protegidos.

Com a finalidade de deslocar o conforto do aluno, que era provocado a considerar a escrita como diálogo com o mundo, algumas perguntas formuladas nos encontros-aula problematizavam um modo de viver dessa camada privilegiada da sociedade, distante da realidade da grande maioria dos jovens: qual a contribuição da educação escolar na garantia dos direitos humanos? O que o dinheiro não pode comprar? As ideologias dominantes prejudicam e beneficiam quem/o quê? Qual a relação entre política e atitudes do cotidiano?

O sentimento de inadequação, a curiosidade e a dúvida, decorrentes do desejo frouxo, poroso, temperamental e desregrado dos jovens tanto podem torná-los mais disponíveis a essa abertura, quanto mais suscetíveis a certas formatações. Muitas afirmações moralmente corretas escritas pelos estudantes eram interpeladas: "Amor não se cobra" - mas por quê? Ou: "os direitos das crianças deveriam ser os primeiros a serem garantidos" - mas por quê? Escrever algo como óbvio incitava questionamentos como uma estratégia para se relacionar com a complexidade dos problemas. Por exemplo, um aluno afirmou e reafirmou a presença e universalidade da música na história do ser humano, mas quebrou sua redundância nas linhas finais, ao defender que a circulação da música é uma forma de conexão e compartilhamento com outras 
culturas no mundo globalizado, em que a tendência é o individualismo. A última frase do texto era preciosa, porque a crítica não recaía sobre a qualidade da música, mas sobre um modo de vida que podia ser alterado por meio dela, uma forma de resistência à globalização, o que permitiu a discussão sobre a música também ser produção da globalização, sobre o aculturamento, assim como a respeito da possibilidade de se preservarem tradições e fazer essas manifestações serem conhecidas pelo mundo todo e perdurarem.

Expressões gastas também mereciam atenção, pois instigavam pouco o leitor: em uma dissertação sobre envelhecimento populacional, o título era "No velho poço do esquecimento" e a conclusão apontava: "Não se podem jogar os idosos no velho poço do esquecimento". Não havia nenhuma provocação sobre o tema, o termo "velho" era literal e "poço", uma redundância metafórica de "esquecimento". Em busca de uma outra saída, a coletânea de textos da proposta foi relida e a palavra "despesa", usada pelo ministro da economia japonês para se referir aos idosos, surgiu como um gancho para uma frase final mais impactante e capaz de retomar a ideia principal do texto: os idosos não podiam ser tratados como peso para a economia. $\mathrm{O}$ aluno, então, fez uma inversão: a despesa não seriam os mais velhos, mas desvalorizar e perder o legado deles, o que teria como resultado prejuízos para as próximas gerações. No texto, a ideia foi registrada: "Esquecer o legado deixado pelos mais velhos acarretará uma despesa paga pelas próximas gerações". Dessa forma, ele evidenciou a relação entre passado e futuro, mas ressignificando a palavra "despesa". Isso o levou a reformular o título: "A despesa a se pagar".

A experiência com escrita que tiveram durante a formação escolar apareceu nos textos e na forma que a língua participava da vida deles. Das mais de dez escolas frequentadas por esses alunos, apenas duas tinham um programa semanal de produção de texto e uma usava o recurso da reescrita como prática das atividades de escrita. Era comum os estudantes escreverem textos uma única vez em um mês, e não terem a escrita como um exercício cotidiano. Não foram raros também os alunos que mostravam a correção de suas redações pelos corretores das escolas e dos cursinhos, sem saber o que fazer com ela, como melhorar o texto a partir dos apontamentos.

Além disso, muitos desses jovens optaram por universidades particulares que definem critérios empobrecidos para avaliar a produção textual. Não há leitor e nem escritor, só há corretor e candidato; não há texto, só formulários; não existem sujeitos se 
fazendo naquele ambiente, apenas mensalidades a serem pagas. Reconhecer a escrita como um tormento ou como uma brincadeira com a língua dependerá, portanto, da construção de mundo que se pretende. Escrever brincando é estar à espreita de faíscas, brechas, fendas na produção de textos, que deem passagem a composições, arranjos, sentidos imprevistos para o que se escreve. $\mathrm{O}$ trabalho com esses estudantes pretendeu criar relevo em um texto chapado, sem volume, fazendo advir uma espessura em que coubessem variações, tanto no texto como no autor.

\section{A escrita como oportunidade de interferir}

No processo de elucidar o percurso de escrita de cada estudante, reconhecemos pontos em que nos interessava intervir: palavras de ordem e naturalizações que dificultavam questionar, criticar, pensar a partir de outras perspectivas; dicotomias que não dialogavam e redações-lista em que não se estabeleciam encadeamentos; expressões como "é importante", "é essencial", porque essas assertivas não bastam se não se discutir para quem, para quê, por quê, quando; o uso de certas palavras como, por exemplo, "ainda" ("ainda vivemos em uma sociedade desigual"), por passar a ideia de que haveria um futuro a chegar sem que fosse preciso tensionar as forças do presente (MACHADO; FONSECA, 2019).

Foram identificados alguns recursos para agir nessas situações durante os encontros-aula: pedir cuidado quando os escritores tratavam acontecimentos como naturais; ampliar a complexidade das situações com textos informativos; contraargumentar e exercitar contra-argumentação; produzir indagações e problematizar, formular perguntas, hesitar; contextualizar as constatações (não "as coisas são assim", mas "quando as coisas são assim?"); ampliar as conexões; acessar a experiência de pensar do escritor, porque sem ela não se sai do senso comum; e, por fim, propor reescritas, à medida que reescrever é parte da prática da escrita que torna possível o movimento do pensamento.

O texto, o meio expressivo, é o campo de atuação direta, mas trabalhar no texto é trabalhar naquele que o produz, é trabalhar o contato do escritor com a sua escrita. É propor uma fricção, um atrito direto, corpo a corpo, em que quem escreve se conecte com aquilo que quer dizer, com um bom grau de liberdade. Portanto, o trabalho com escrita depende de alguma disposição do estudante: não é possível ele "assistir a uma aula"; ele é convocado a participar: escrever é ação no mundo. 
A noção de criação, proposta por Deleuze (2013), como produto da ressonância entre existências, enseja pensarmos no professor e no aluno como intercessores um do outro. Com gestos instauradores, um faz existir o outro e ambos legitimam formas de existência mais frágeis e evanescentes, dão o direito de existir a formas de vida imprevistas e a escritas minoritárias. Como coloca Lapoujade (2017: 99), "[...] existimos pelas coisas que nos sustentam, assim como sustentamos as coisas que existem através de nós, numa edificação ou numa instauração mútua. Só existimos fazendo existir." Instaurar, assim, é legitimar a beleza do que se viu e se produziu nesse encontro edificante, por isso quem legitima não é o que importa, mas o que foi visto, o que foi produzido.

O professor poderia funcionar como um produtor de interferências para o escrever do aluno ser experimentação de si, ao se colocar como leitor do texto do aluno. Mas um leitor que não se contenta em ser apenas destinatário de uma mensagem ou "vigilante da língua", almejando ser também compositor desse texto, no sentido de participar ativamente dessa produção, disponibilizar sua escuta, seus conhecimentos e forças para fazer falar o texto do aluno e o aluno fazer-se no texto, ou, ao menos, para provocar um deslocamento que não é imediatamente transposto em prática, mas atua no seu modo de pensar. Kastrup (2005:1287) caminha nesse sentido ao sugerir que "ensinar é, em grande parte, compartilhar experiências de problematização. Estas podem ser fugazes, emergindo no campo da percepção e se dissipando em seguida. Mas é imprescindível a manutenção de sua potência para a invenção de novas subjetividades e novos mundos".

Na afirmação de Foucault (1998: 13): "Existem momentos na vida em que a questão de saber se se pode pensar diferentemente do que se pensa, e perceber diferentemente do que se vê, é indispensável para continuar a olhar ou a refletir" também é possível se insinuar a presença do professor, que autorizaria e encorajaria um outro pensamento.

O acompanhamento da escrita de um outro envolve um posicionamento ativo nos jogos de poder, em que ocorrem contradições, propostas de conciliação, tomada de posicionamentos, produção de encadeamentos, deslocamentos e compreensão de outros pontos de vista. Enfim, o disparador de todas essas ações podem ser os esforços para ingressar na faculdade, mas desenvolver esse tipo de escrita em que nos tornamos autores dependerá de disposições que não se reduzem a essa necessidade. 


\section{Reverberações}

Esse trabalho dispara questões sobre o que estamos fazendo com nossa escrita e conosco nas instâncias acadêmicas e em que medida o uso da escrita na universidade se diferencia do uso preponderantemente protocolar e impessoal da escrita na escola ou o perpetua, visto que a escrita-tarefa-escolar inevitavelmente é transposta ao Ensino Superior pelos estudantes e que as universidades, subjugadas pelo espírito empresarial, são solicitadas a manter a produtividade acima de tudo e produzem uma atmosfera adoecedora e, consequentemente, uma escrita sem vitalidade, que reproduz relações de poder.

Entretanto, se acreditamos que o jogo de poder também é operado nas formas que escrevemos nossas pesquisas, inventar, propor e desenvolver algumas estratégias de exercícios de escrita é uma forma de agir diante da miséria de uma escrita protocolar, inofensiva e estéril, que não tensiona o pensamento.

Deleuze e Guattari (2000) argumentam que um livro tanto pode funcionar como máquina de guerra, forma que produz novos sentidos e expande modos de vida, quanto como aparelho de Estado, mecanismo de reprodução da ordem estabelecida e de exercício de poder sobre um povo menor. Assim também podemos considerar o próprio ato de escrever: a escrita tanto pode ser um mecanismo de reprodução do pensamento dominante, de conformação aos discursos hegemônicos, quanto pode funcionar como resistência a essa dominação, como experimentação de novos modos de vida - um processo de atualização do que compõe ou deixa de compor o território de expressão daquele que escreve.

Escrever é um empreendimento de saúde, segundo Deleuze (2006), quando inventa um povo que falta, que está por se fazer, ou seja, quando dá voz a um povo menor, quando, em suas linhas, faz falar outra coisa que não a predefinida, inacabada e, por isso, revolucionária, pois em fuga dos clichês esvaziados de sentido e em busca de um dizer que propulsiona a vida, que a reafirma e multiplica.

O exercício de uma escrita libertadora, no campo acadêmico, requer agir nas amarras que constituem seus aprisionamentos, presentes em fundamentos que se tornam paradas obrigatórias ou cadeiras cativas, e em formalismos que impedem acolher a experiência produzida pela pesquisa no pesquisador: "[...] o jogo da construção da liberdade só pode ser jogado como um jogo coletivo, de mútuas interações e relações, em que as ações de uns implicam ações de outros. Um jogo em que uns se fazem livres 
aprendendo da liberdade dos outros; em que uns se fazem livres na medida em que ensinam a liberdade aos outros." (GALLO, 2006: 188).

Alguns autores têm se debruçado sobre os perigos de uma escrita encarcerada em modalidades protocolares. Uma experiência mais arejada com a escrita, em que se experimente a língua e a si mesmo, seria menos da ordem da informação, da narratividade ou da opinião, e mais da ordem dos afetos que, ao passarem por nós, nos formam e nos transformam - o que Aquino (2009) nomeou de escrita-acontecimento. Dessa maneira, no ensino e aprendizagem da escrita, interessaria mais a surpresa da performance do que a fidedignidade às normas e verdades instituídas. Nessa mesma direção, Larrosa (2004) propõe uma escrita-ensaio, uma escrita pensante, experimental, em que se abre a possibilidade de uma nova experiência do presente. $\mathrm{O}$ presente passaria a ser experiência quando o estranhamos, o problematizamos e o tomamos como espaço em que a subjetividade pode ser produzida. A escrita-ensaio seria propiciada, então, por uma forma de trabalho não regulada, que permitiria experimentar e criar modos inéditos de existir. Silva et al. (2012) defendem que escrever é parte da atividade de pesquisar, não apenas como produção final e apresentação pública da pesquisa, mas principalmente como método, como recurso, dispositivo para pensar o que não pode ser pensado, testar, experimentar, comparar, levantar hipóteses, encontrar saídas, ver outros pontos de vista, acolher imprevistos. Esses pesquisadores se apoiam em Latour para propor a escrita como laboratório da pesquisa, por ser uma atividade em que, como "num laboratório, algumas substâncias se misturam, interagem, reagem, produzem outras inéditas substâncias e realidades" (SILVA et al., 2012: 179). Corazza (2006) sugere uma escrita-artista e incerta ao docente, capaz de construir subjetividades desviantes das ordens hegemônicas.

Acontecimento. Ensaio. Laboratório. Arte. Ensinar a escrever, dessa forma, seria provocar o estudante a acessar suas vivências, a problematizar, desafiá-lo a deslocar suas certezas, a experimentar, o que requereria do professor um modo de docência que, mais do que mediar a apreensão de uma aprendizagem predeterminada, participa da criação da aprendizagem e intercede por ela. Para isso, o professor exercitaria seu lado pesquisador, curioso, que se questiona e se provoca e, assim, consente e aviva a curiosidade de seus alunos. Haveria, então, uma reciprocidade na relação de ensinar alguém quando se entende que ensinar também é aprender: "[...] é ela que nos permite 
dizer que o exercício do cuidado do outro, pela educação, pode redundar num cuidado de si, como uma espécie de 'reflexo'." (GALLO, 2006: 186).

As considerações desses autores se somam aos desafios apresentados por Foucault $(2006,2005)$ quanto à possibilidade de ação perante o esquadrinhamento que submete o sujeito, na medida em que as próprias regras e modelos de socialização incitariam a criação de alternativas, de formas de resistência em que a escrita é analisada como possibilidade de ação nas malhas do poder.

Escrever uma tese (ou qualquer outra produção textual acadêmica) é disputar formas de existência e, sendo assim, contém uma dimensão ético-política, na medida em que desloca modos de ser e de pensar daqueles que a escrevem e daqueles que a leem. Este artigo versa sobre uma tese de doutorado composta por uma pesquisadora na vida acadêmica, em que foram necessários esforços, parcerias e várias versões para romper com uma escrita que tendia também em generalizações sobre o outro - tendência imbuída em nós.

Ao ressaltar o perigo das naturalizações e generalizações no pensamento, este artigo toma partido: todo acontecimento é agenciado em relações de poder e saber em constante produção. Escrever é ação nesse agenciamento e, portanto, toda escrita é ato. Considerar que a produção de texto produz mundo enseja assumir o processo de escrita engendrando o pesquisador e a pesquisa.

\section{Referências}

AQUINO, Julio. Docência, poder e liberdade: dos processos de governamentalização à potência de existir nas escolas. 2009. 210 f. Tese (Livre Docência em Governabilidade, ética e educação) - Faculdade de Educação, Universidade de São Paulo, São Paulo, 2009. Disponível em: http://www.teses.usp.br/teses/disponiveis/livredocencia/48/tde-19032013093316/pt-br.php Acesso em 10 mar. 2019.

AVELINO, Nildo. Foucault e a racionalidade (neo)liberal. Revista Brasileira de Ciência Política, Brasília, n. 21, p. 227-284, set.-dez. de 2016.

BRITO, C. Escrita no vestibular: quando o sujeito (des)aparece. 2004. 377 f. Dissertação (Mestrado em Linguística Aplicada) 2004. Universidade de Campinas, São Paulo, 2004.

CASTALDO, Marcia. Redação no vestibular: a língua cindida. 2009. 277 f. Tese (Doutorado em Educação) - Universidade de São Paulo, São Paulo, 2009.

CORAZZA, S. Artistagens: filosofia da diferença e educação. Belo Horizonte: Autêntica, 2006. 
COSTA VAL, Maria. Redação e textualidade. 3.ed. São Paulo: Martins Fontes, 2006.

DELEUZE, Gilles. Conversações. 3. ed. São Paulo: Ed. 34, 2013.

DELEUZE, Gilles. Crítica e clínica. 2. ed. São Paulo: Editora 34, 2006.

DELEUZE, Gilles; GUATTARI, Félix. Mil platôs - capitalismo e esquizofrenia, vol. 1. São Paulo: Ed. 34, 2000.

DOMÈNECH, M.; TIRADO, F.; GÓMEZ, L. A dobra: psicologia e subjetivação. In: SILVA, T. (org.). Nunca fomos humanos - nos rastros do sujeito. Belo Horizonte: Autêntica, 2001.

FOUCAULT, Michel. A hermenêutica do sujeito. São Paulo: Martins Fontes, 2006.

FOUCAULT, Michel. História da sexualidade 3: o cuidado de si. Rio de Janeiro: Graal, 2005.

FOUCAULT, Michel. História da sexualidade 2: o uso dos prazeres. Rio de Janeiro: Graal, 1998.

GALLO, Silvio. Cuidar de si e cuidar do outro: implicações éticas para a educação dos últimos escritos de Foucault. In: KOHAN, W.; GONDRA, J. (orgs). Foucault 80 anos. Belo Horizonte: Autêntica, 2006.

KASTRUP, V. Políticas cognitivas na formação do professor e o problema do devirmestre. Campinas. Educação e Sociedade, vol. 26, n. 93, p. 1273 -1288, set./dez. 2005.

LAPOUJADE, David. As existências mínimas. São Paulo: n-1 edições, 2017.

LARROSA, Jorge. A Operação Ensaio: sobre o ensaiar e o ensaiar-se no pensamento, na escrita e na vida. Educação e Realidade, Porto Alegre, v. 29, n. 1, p. 27-43, jan-jun 2004.

MACHADO, Adriana; FONSECA, Paula. A escrita endereçada como prática de formação e construção de realidade. Mnemosine, vol. 15, n. 1, p. 4 - 22, 2019.

Ó, Jorge; AQUINO, Julio. Em direção a uma nova ética do existir: Foucault e a experiência da escrita. Educação e Filosofia, Uberlândia, v. 28, n. 55, p. 199231, jan./jun. 2014.

OSAKABE, H. Redações no vestibular: provas de argumentação. Cadernos de Pesquisa, São Paulo, n. 23, p. 51-59, 1977.

PÉCORA, Alcir. Problemas de redação. 5. ed. São Paulo: Martins Fontes, 1999.

PIETRI, Emerson. Ensino da escrita na escola: processos e rupturas. Cadernos de Educação, Pelotas, p. 133-160, set./dez. 2010. 
ROCCO, Maria Thereza. Crise na linguagem: a redação no vestibular. São Paulo: Mestre Jou, 1981.

SPOSITO, Marília; SOUZA, Raquel; SILVA; Fernanda. A pesquisa sobre jovens no Brasil: traçando novos desafios a partir de dados quantitativos. Educação $e$ Pesquisa, local, v. 44, p. e170308, $1^{\circ}$ jan. 2018.

SPOSITO, Marília; SOUZA, Raquel. Desafios da reflexão sociológica para a análise do ensino médio no Brasil. In: KRAWCZYK, N. (org.). Sociologia do ensino médio: crítica ao economicismo na política educacional. São Paulo: Cortez, 2014. p. 33-62.

VEIGA-NETO, Alfredo. Foucault e a Educação. Belo Horizonte: Autêntica, 2007.

SILVA, Thais; MORAES, Marcia; COUTO, Carolina; TREBISACCE, Dandara; VAZ, Juliana; PESTANA, Keyte; MIGNON, Larissa; PAULA, Lia; CORRÊA, Lucas; FRANÇA, Maíra; RAPOSO, Rafael. EscreverCOM: com quem? Com o quê? Por quê? Revista Polis e Psique, vol. 7, n. 2, p. 176-190, 2017.

Sílvia Galesso Cardoso Doutora pela Faculdade de Educação da USP e professora autônoma de produção textual Email: $\underline{\text { silviagalesso@gmail.com }}$

Adriana Marcondes Machado Docente dos cursos de graduação e pós-graduação do Instituto de Psicologia da USP e coordenadora do Serviço de Psicologia Escolar do IPUSP

E-mail: $\underline{\text { adrimarcon@uol.com.br }}$

Dra. Teresa Cristina Rego

Docente dos cursos de graduação e pós-graduação da Faculdade de Educação da USP

E-mail: teresare@usp.br

\footnotetext{
1 Tese intitulada Subjetividade e escrita argumentativa: encontros e desencontros na composição do texto, de autoria de Sílvia Galesso, sob orientação da professora doutora Teresa Cristina Rego. A defesa se deu em junho de 2019, na Faculdade de Educação da USP, e contou com arguição da professora doutora Adriana Marcondes. O documento pode ser acessado no seguinte endereço:

https://www.academia.edu/42557275/UNIVERSIDADE_DE_S\%C3\%830_PAULO FACULDADE_DE EDUCA\%C3\%87\%C3\%830_S\%C3\%8DLVIA_GALESSO_CARDOSO

${ }^{2}$ Esses desdobramentos compõem com a proposta de criar um laboratório de escrita para profissionais em formação no Instituto de Psicologia da USP, em um projeto de pós-doutorado.

${ }^{3}$ Encontros entre centenas de jovens de periferia em shoppings de São Paulo, marcados pela internet.
} 


\footnotetext{
${ }^{4}$ Atos mobilizados inicialmente contra o aumento das tarifas de ônibus nas principais capitais do país, que tomaram força após repressão policial e se expandiram em protestos contra a falta de qualidade dos serviços públicos e contra a corrupção na política.
}

Reformas aprovadas no governo de Michel Temer e Jair Bolsonaro, respectivamente, ambas sob a justificativa de serem fundamentais para melhorar a situação econômica do Brasil, apesar de fragilizarem a condição de vida dos trabalhadores e dos idosos.

5 Reformas aprovadas no governo de Michel Temer e Jair Bolsonaro, respectivamente, ambas sob a justificativa de serem fundamentais para melhorar a situação econômica do Brasil, apesar de fragilizarem a condição de vida dos trabalhadores e dos idosos.

6 Disponível em: http://download.inep.gov.br/educacao basica/portal ideb/press-kit/2017/presskit_ideb2017.pdf Acesso em 19 jan. 2019. 